\title{
Crustal Motion Models Developed for Version 3.2 of the Horizon- tal Time-Dependent Positioning Utility
}

\author{
Richard A. Snay, ${ }^{1, *}$ Jeffrey T. Freymueller ${ }^{2}$ and \\ Chris Pearson $^{3}$ \\ ${ }^{1}$ National Geodetic Survey (retired), 9505 Aspenwood \\ Court, Montgomery Village, Maryland, 20886, USA \\ ${ }^{2}$ Geophysical Institute, Univ. of Alaska Fairbanks, 903 \\ Koyukuk Dr., Fairbanks, Alaska, 99775, USA \\ ${ }^{3}$ Surveying Department, Otago Univ., Box 56, Dunedin, \\ New Zealand
}

\begin{abstract}
The Horizontal Time-Dependent Positioning (HTDP) software allows users to transform positional coordinates across time and between spatial reference frames. To provide this capability, the software includes numerical models for estimating interseismic horizontal crustal velocities in and around the United States, as well as numerical models for estimating the displacements associated with major (magnitude $>6.0$ ) earthquakes in these same areas. Version 3.2 of HTDP was released in August 2012. This HTDP version introduces: (a) an improved model for estimating interseismic horizontal velocities in Alaska, (b) a model for estimating the postseismic motion associated with the M7.9 Denali Fault earthquake that occurred in central Alaska on November 3, 2002, and (c) an improved model for estimating interseismic horizontal velocities in the region of the conterminous United States, which is located east of longitude $107^{\circ} \mathrm{W}$. The development and nature of these new models are discussed in this paper.
\end{abstract}

Keywords. Crustal deformation, dynamic datums, computer software, tectonic motion, earthquake.

\section{Introduction}

In 1992, NOAA's National Geodetic Survey (NGS) introduced the Horizontal Time-Dependent Positioning (HTDP) software. HTDP allows users to transform positional coordinates across time and between spatial reference frames. In particular, the current version of HTDP enables users to perform each of the following functions:

Corresponding author: Richard A. Snay, Surveying \& Geospatial Engineering National Geodetic Survey (retired), 9505 Aspenwood Court, Montgomery Village, Maryland, 20886, USA.

E-mail: rssnay@aol.com.

Received: March 01, 2013. Accepted: June 24, 2013.
- Estimate interseismic horizontal crustal velocities

- Estimate the horizontal crustal displacements between two dates

- Transform positional coordinates from one reference frame to another and/or from one date to another

- Transform certain types of geodetic observations from one reference frame to another and/or from one date to another

- Transform crustal velocities from one reference frame to another.

HTDP supports these functions in recent realizations of the North American Datum of 1983 (NAD 83), as well as in all realizations of the International Terrestrial Reference System (ITRS) [2] and all realizations of the World Geodetic System of 1984 (WGS 84) [30].

HTDP supports these functions by incorporating numerical models for estimating interseismic horizontal crustal velocities and numerical models for estimating the displacements associated with 29 major earthquakes (most with moment magnitude $>6$ ) that have occurred in and around the United States since 1934. Every so often, NGS releases a new version of HTDP that introduces a completely new crustal motion model or a revision to an existing model, or when additional capabilities have been added to the software. In August 2012, NGS released version 3.2 of HTDP (HTDP_v3.2), which introduced:

- An improved model for estimating interseismic horizontal crustal velocities in Alaska

- A model for the postseismic motion associated with the M7.9 Denali Fault earthquake that occurred in central Alaska on November 3, 2002

- An improved model for estimating interseismic horizontal crustal velocities in the region of the conterminous United States (CONUS) located east of longitude $107^{\circ} \mathrm{W}$.

The development and nature of these three models will be discussed in this paper. HTDP_v3.2 also introduces a minor refinement to the Western CONUS model encoded into HTDP_v3.1 [23]. This refinement, which is mentioned here only for the sake of completeness, involves the use of slightly newer velocity estimates at several continuous GPS sites. 


\begin{tabular}{lllll}
\hline Region & Latitude Range & Longitude Range & $\begin{array}{l}\text { Node } \\
\text { Spacing (minutes) }\end{array}$ & Reference \\
\hline San Andreas & $35.8^{\circ} \mathrm{N}-36.79 \mathrm{~N}$ & $120.51^{\circ} \mathrm{W}-121.8^{\circ} \mathrm{W}$ & 0.6 & {$[23]$} \\
Southern California & $31^{\circ} \mathrm{N}-36^{\circ} \mathrm{N}$ & $114^{\circ} \mathrm{W}-121^{\circ} \mathrm{W}$ & 3.75 & {$[23]$} \\
Northern California & $36^{\circ} \mathrm{N}-40^{\circ} \mathrm{N}$ & $119^{\circ} \mathrm{W}-125^{\circ} \mathrm{W}$ & 3.75 & {$[23]$} \\
Pacific Northwest & $40^{\circ} \mathrm{N}-49^{\circ} \mathrm{N}$ & $122^{\circ} \mathrm{W}-125^{\circ} \mathrm{W}$ & 3.75 & {$[23]$} \\
Western CONUS & $31^{\circ} \mathrm{N}-49^{\circ} \mathrm{N}$ & $107^{\circ} \mathrm{W}-125^{\circ} \mathrm{W}$ & 15.0 & {$[23]$} \\
Eastern CONUS & $24^{\circ} \mathrm{N}-50^{\circ} \mathrm{N}$ & $66^{\circ} \mathrm{W}-110^{\circ} \mathrm{W}$ & 30.0 & This publication \\
St. Elias, Alaska & $56.5^{\circ} \mathrm{N}-63^{\circ}$ & $140^{\circ} \mathrm{W}-148^{\circ} \mathrm{W}$ & 15.0 & This publication \\
South-Central Alaska & $53.25^{\circ} \mathrm{N}-65.75^{\circ} \mathrm{N}$ & $143.25^{\circ}-162^{\circ} \mathrm{W}$ & 15.0 & This publication \\
Southeast Alaska & $54^{\circ} \mathrm{N}-63^{\circ} \mathrm{N}$ & $130^{\circ} \mathrm{W}-142^{\circ} \mathrm{W}$ & 15.0 & This publication \\
Mainland Alaska & $56^{\circ} \mathrm{N}-73^{\circ} \mathrm{N}$ & $130^{\circ} \mathrm{W}-170^{\circ} \mathrm{W}$ & 15.0 & This publication \\
\hline
\end{tabular}

Table 1. Velocity grids used in HTDP.

Users may run the latest version of HTDP interactively on the world-wide-web at geodesy.noaa.gov/TOOLS/ Htdp/Htdp.shtml. They may also download the file, HTDP.for, from this web site. This file contains Fortran90 source code for HTDP. A user will need to compile and link this source code to create executable code that can be run directly on his/her computer. The web site also contains

- An HTDP User's Guide, containing instructional exercises

- Sample data files for use with the instructional exercises

- A LOG summarizing revisions to HTDP since its inception

- Copies of relevant publications

- Several horizontal crustal motion maps

\section{Estimating horizontal crustal velocities}

HTDP quantifies horizontal crustal motion in terms of

- constant interseismic velocities

- coseismic motion, i.e., abrupt changes in positional coordinates, each of which happens within a few minutes of an earthquake

- postseismic motion, i.e., the transient motion following an earthquake which - depending on the earthquake's magnitude - may remain geodetically measurable from as short as a few days to as long as several decades.

Other types of horizontal crustal motion - such as the periodic motion associated with tidal loading and the transient motion associated with slow earthquakes - exist, but the current version of HTDP does not address these other types.
To quantify crustal velocities, HTDP incorporates several regions, with each region being one of two types. With the first type, HTDP employs a 2D rectangular grid (in latitude and longitude) spanning the region for which velocities at the grid nodes have been previously determined from geodetic and geophysical data. With this type of region, HTDP uses bilinear interpolation to compute the horizontal velocity at a user-specified location by using stored horizontal velocities for the grid nodes, in particular, the four grid nodes forming the corners of the 2D grid cell containing this location. Table 1 lists the ten regions of this type and provides pertinent information about these regions.

With the second type of region, HTDP uses rigid tectonic plate models to estimate horizontal velocities via the equations

$$
\begin{aligned}
& V_{x}=\dot{T}_{x}+\dot{R}_{y} \cdot z-\dot{R}_{z} \cdot y \\
& V_{y}=\dot{T}_{y}+\dot{R}_{z} \cdot x-\dot{R}_{x} \cdot z \\
& V_{z}=\dot{T}_{z}+\dot{R}_{x} \cdot y-\dot{R}_{y} \cdot x
\end{aligned}
$$

Here $(x, y, z)$ denote Earth-centered, Earth-fixed Cartesian coordinates for a user-specified location; $\left(V_{x}, V_{y}, V_{z}\right)$ denote the $3 \mathrm{D}$ velocity at this location; $\left(\dot{T}_{x}, \dot{T}_{y}, \dot{T}_{z}\right)$ denote the the translation rates along the $x$-axis, $y$-axis and $z$-axis, respectively; and $\left(\dot{R}_{x}, \dot{R}_{y}, \dot{R}_{z}\right)$ denote the rotation rates about these three axes. HTDP then converts these velocities to horizontal and vertical velocities. Table 2 lists the seven regions of this type and provides some pertinent information about these regions. For the geographic boundaries of these seven regions, HTDP_v3.2 uses the plate boundaries published by Bird [5].

When a user specifies a location, HTDP will step through the 17 regions in a specific order until it finds the first region that contains the specified location. It will then use the model for this region to estimate the velocity at this location. Gridded regions all precede the tectonic plates. The 


\begin{tabular}{|c|c|c|c|c|c|c|c|c|}
\hline Tectonic Plate & Frame & $\begin{array}{l}\dot{T}_{x} \\
\mathrm{~mm} / \mathrm{yr}\end{array}$ & $\begin{array}{l}\dot{T}_{y} \\
\mathrm{~mm} / \mathrm{yr}\end{array}$ & $\begin{array}{l}\frac{\dot{T}_{z}}{\mathrm{~mm} / \mathrm{yr}}\end{array}$ & $\begin{array}{l}\dot{R}_{x} \\
\mathrm{nrad} / \mathrm{yr}\end{array}$ & $\begin{array}{l}\dot{R}_{y} \\
\mathrm{nrad} / \mathrm{yr}\end{array}$ & $\begin{array}{l}\dot{R}_{z} \\
\mathrm{nrad} / \mathrm{yr}\end{array}$ & Source \\
\hline North America & ITRF2008 & 0.41 & 0.22 & 0.41 & 0.170 & -3.209 & -0.485 & [3] \\
\hline Caribbean & ITRF2008 & 0.41 & 0.22 & 0.41 & 0.235 & -5.275 & 3.219 & [3] \\
\hline Pacific & ITRF2008 & 0.41 & 0.22 & 0.41 & -1.993 & 5.023 & -10.501 & {$[3]$} \\
\hline Juan de Fuca & ITRF2008 & 0.41 & 0.22 & 0.41 & 6.626 & 11.708 & -10.615 & {$[11]^{*}$} \\
\hline Cocos & ITRF2008 & 0.41 & 0.22 & 0.41 & -10.390 & -14.954 & 9.148 & {$[11]^{*}$} \\
\hline Mariana & ITRF2000 & 0.00 & 0.00 & 0.00 & -0.097 & 0.509 & -1.682 & [27] \\
\hline Philippine Sea & ITRF2008 & 0.41 & 0.22 & 0.41 & -0.841 & 3.989 & -10.626 & {$[11]^{*}$} \\
\hline
\end{tabular}

* [11] provides the motion of this plate relative to the Pacific plate. For each of the three rates $\dot{R}_{x}, \dot{R}_{y}, \dot{R}_{z}$ (contained in [11]), its value was added to the corresponding ITRF2008 rate of the Pacific plate (as given in [3]) to obtain the corresponding ITRF2008 rate for the plate.

Table 2. Plate motion rates encoded into HTDP (positive rotation rates are counterclockwise).

gridded regions are ordered as they appear in Table 1, from top to bottom. The tectonic plates are ordered as they appear in Table 2, from top to bottom. If the specified location is not contained in any of the 17 regions, then HTDP outputs a message to the effect that it is unable to estimate the velocity for this location.

\section{Estimating crustal displacements}

HTDP may be used to estimate the horizontal crustal displacement from time $t_{1}$ to time $t_{2}$ at a specified location. The estimated displacement equals the velocity at this location multiplied by the time difference $\left(t_{2}-t_{1}\right)$ plus all coseismic and postseismic displacements that have occurred between these two times. The user may opt to allow HTDP to estimate the velocity to be used in this procedure, or he/she may interactively supply the velocity to be used.

HTDP uses the equations of dislocation theory [20] to quantify coseismic motion for 29 major earthquakes that have occurred in and around the United States and/or its territories since 1934. The earthquakes, whose dislocation models are encoded into HTDP, are listed in the "HTDP User's Guide" available at geodesy.noaa.gov/TOOLS/ Htdp/Htdp.shtml. HTDP uses the equation

$$
\begin{aligned}
& D_{i j}(\varphi, \lambda, t)=A_{i j}(\varphi, \lambda) \cdot\left[1.0-e^{\left(-\frac{\left(t-\tau_{i}\right)}{\nu_{i}}\right)}\right], \quad \text { if } \tau_{i}<t \\
& D_{i j}(\varphi, \lambda, t)=0, \quad \text { if } \tau_{i}>t
\end{aligned}
$$

to model the cumulative postseismic motion $D_{i j}(\varphi, \lambda, t)$ from time $\tau_{i}$ to time $t$, which is associated with earthquake $i$ and dimension $j$ ( $j=$ north, east, or up) and which occurred at the location with latitude $\varphi$ and longitude $\lambda$. Here $A_{i j}(\varphi, \lambda)$ equals the amplitude (in meters) associated with earthquake $i$ and dimension $j$ at the location with latitude $\varphi$ and longitude $\lambda, \tau_{i}$ equals the time of occurrence of earthquake $i$, and $\nu_{i}$ equals the relaxation constant associated with earthquake $i$. Note that as $t \rightarrow \infty$, $D_{i j}(\varphi, \lambda, t) \rightarrow A_{i j}(\varphi, \lambda)$.

HTDP_v3.2 contains a postseismic motion model for only the M7.9 Denali Fault earthquake that occurred in central Alaska on November 3, 2002. This model provides amplitudes $A_{i j}(\varphi, \lambda)$ at the nodes of a $2 \mathrm{D}$ rectangular grid in latitude and longitude. HTDP uses bilinear interpolation to estimate corresponding amplitudes at other geographic locations within the grid's span. For other earthquakes, their postseismic motion has been neglected or incorporated into corresponding models for coseismic motion. For a discussion of the latter, see [22].

\section{Alaskan data}

HTDP_v3.2 introduces a significant upgrade to the Alaskan velocity model that was encoded into HTDP_v3.1 [23], which, in turn, was an upgrade to the Alaskan velocity model published by Freymueller et al. [15]. All three models are based on similar sets of GPS data; however, the data were reprocessed and additional continuous GPS data added before developing the HTDP_v3.2 model. Also, a slightly longer time interval (1992-2010) of data was employed in developing the HTDP_v3.2 model. The data include episodic GPS measurements observed at 600 sites, plus continuous GPS measurements observed at 76 sites. The continuous GPS sites mostly belong to the Plate Boundary Observatory (PBO) < pboweb.unavco.org $>$ or the U.S. CORS network geodesy.noaa.gov/CORS/, plus a few operated by the University of Alaska Fairbanks. Velocity solutions relative to ITRF2008 were estimated for three different time intervals due to the coseismic and postseismic displacements of the 2002 Denali Fault earthquake: 
pre-Denali (1993-2002), cross-Denali (1993-2007), and alltime (1992-2010). For sites close to the rupture surface, within $\sim 200 \mathrm{~km}$, only the pre-earthquake data can be used to estimate the steady velocity because of the large postseismic transient deformation. The cross-Denali solution was used for episodic sites located close enough to have a significant coseismic displacement, but not a significant postseismic displacement due either to distance or measurement history. This solution applied a correction for the Denali Fault earthquake's coseismic displacement based on Hreinsdóttir at al. [17], but did not estimate seasonal variations or station-specific offsets in the positional time series. The all-time solution included only the continuous sites that did not experience significant postseismic deformation. The all-time solution includes steps in the positional time series at the time of the Denali Fault earthquake (where needed), as well as at the times of a few additional station-specific offsets. Annual and semi-annual seasonal variations were estimated, except for a few sites with consistent seasonal data gaps. The final set of velocities, used for modeling, employed the all-time velocity vectors where possible, and otherwise either pre-Denali velocity vectors or cross-Denali velocity vectors were employed following the selection process applied by Freymueller et al. [15].

The derived ITRF2008 velocities were converted to velocities relative to the stable interior of the North America plate by using the GEODVEL model [4], plus a $1.2 \mathrm{~mm} / \mathrm{yr}$ translation rate for the geocenter in the $\mathrm{z}$-direction, i.e., the direction parallel to Earth's pole of rotation. These converted velocities were then employed to develop the various components of the Alaskan velocity model relative to stable North America. Subsequently, the modeled velocities were converted back to ITRF2008 for their incorporation into HTDP_v3.2 using the inverse of the transformation described above. (As previously mentioned, HTDP enables users to transform ITRF2008 velocities to velocities relative to other popular spatial reference frames.) The HTDP_v3.2 model differs from both the HTDP_v3.1 model and the Freymueller et al. [15] model, because the earlier two models started with velocities relative to ITRF2000/IGb00 and used a different transformation for converting these velocities to North American velocities and back. The few sites with large velocity changes are all episodic sites that have only 2 or 3 surveys, and often have one of those surveys using a different antenna type than that used for the other surveys at the site. The antennas make a difference because the old solutions used relative phase center calibrations while the new solutions use absolute phase center calibrations [26]. For continuous GPS sites and long-running episodic sites, the typical horizontal velocity difference is only a few tenths of a millimeter per year.

\section{Overview of Alaskan velocity model}

The Alaskan interseismic velocity model is a composite of four separate models, one for each of four rectangular regions identified in Table 1 . Figure 1 presents interseismic velocities relative to stable North America, as obtained by transforming the ITRF2008 velocities encoded in HTDP_v3.2. The green line segments, appearing in Figure 1, designate the effective boundaries for the four regional models. Each of the four polygonal regions appearing in Figure 1 is completely contained in its corresponding rectangular region identified in Table 1 . Because the four rectangular regions overlap one another, they were ordered as listed in Table 1 so that when an HTDP user specifies a location, this software will compute the location's velocity by using only the model for the first region containing this location. Note that the rectangular St. Elias region was converted into a six-sided region by removing a rectangular area in this region's northwest corner, so that the interpolated velocities for this grid would blend more smoothly with the block model velocities for the adjacent Southcentral region. HTDP allows its developers to so reduce the spatial extent of a rectangular region to that located inside a simple closed polygon, provided the polygon is contained entirely within the rectangular extent of the region's grid. Unfortunately, velocity discontinuities across other regional boundaries could not be mitigated reliably, because these boundaries mostly pass through areas where few data are available.

For two of the four regions (Southeast Alaska and Southcentral Alaska), elastic block models provide the basis for a geophysically reasonable representation of the velocity field. For an elastic block model, the region is partitioned into a collection of blocks that are bounded by geologic faults. Each fault is assumed to slip freely at a constant rate below some depth with either less or no slip occurring above this depth. The slip differential causes the blocks to deform elastically in accordance with the dislocation equations of Okada [20]. In the absence of the slip differentials, the blocks would move rigidly across the Earth's surface where the deep fault slip reflects the relative motion between the blocks adjacent to this fault (like a rigid plate model). In the case of South-central Alaska, the model includes two other components in addition to the elastic block model: (a) postseismic deformation due to the 1964 M9.2 Prince William Sound earthquake and (b) an elastic coupling model for the interaction across the interface between the subducted part of the Pacific plate and the overriding plates (North America and Bering). In the other two regions: St. Elias and Mainland Alaska, interpolation of the velocity vectors was used because the associated geophysical models are complex and poorly constrained. Note that the four regions, in combination, do not span the entire extent of the Aleutian Islands. After generating the four velocity models, corresponding velocities at the nodes of a $2 \mathrm{D}$-grid (in latitude 


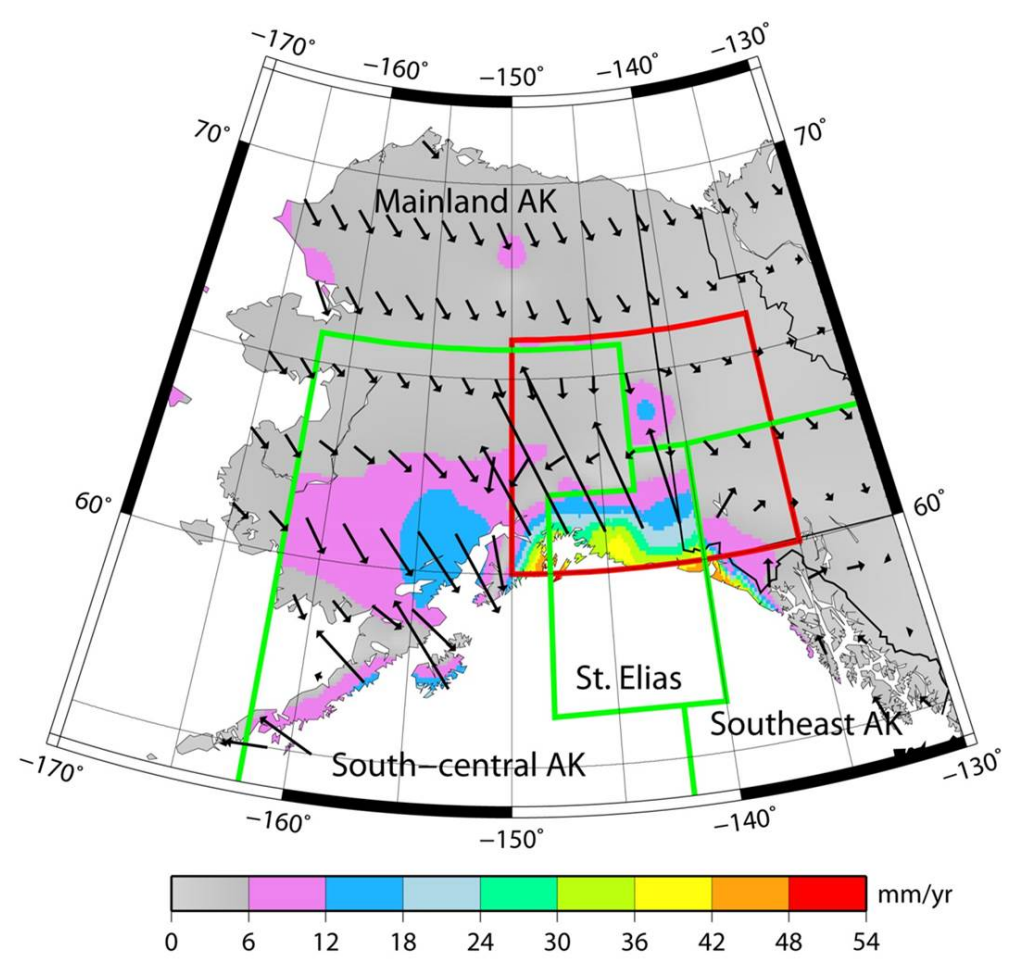

Figure 1. Composite Alaskan interseismic velocity field relative to stable North America. Colors indicate velocity magnitudes and arrows indicate velocity magnitudes and directions. Green line segments designate boundaries for the four regional velocity models. The red rectangle designates the boundary for the postseismic motion model associated with the 2002 Denali Fault earthquake.

and longitude) with a spacing of $15^{\prime}$ by $15^{\prime}$ 'were then computed; one grid for each of the four regions.

The red rectangle appearing in Figure 1 bounds the area for which HTDP_v3.2 includes a model for the postseismic motion associated with the M7.9 Denali Fault earthquake of November 3, 2002.

\subsection{Southeast Alaska velocity model}

The deformation in southeast Alaska is dominated by rightlateral strike slip across the fault systems in the boundary zone between the Pacific plate and the North America plate. These fault systems strike nearly parallel to the orientation of the southeastern Alaskan panhandle. Elliott et al. [13] developed an elastic block model for this region which reveals that present-day tectonics in southeast Alaska is also strongly influenced by the collision of the Yakutat block, which is wedged between the Pacific plate and the North America plate, with that part of Alaska located to the block's immediate north. Strain from this collision is transferred far to the east of the strike-slip system. Elliott et al. [13] also developed a model for the glacial isostatic adjustment (GIA) occurring in southeast Alaska. These authors used this GIA model to revise the available GPS-derived velocity vectors prior to developing their block model. HTDP_v3.2 uses the block model of Elliott et al. [13] with the GIA-related motion restored.

\subsection{South-central Alaska velocity model}

Deformation in south-central Alaska is dominated by subduction of the Pacific plate beneath the North America and the Bering plates [10]. The region is also still experiencing measurable postseismic deformation associated with the M9.2 Prince William Sound earthquake of 1964. Suito and Freymueller [29] developed a velocity model for this region which includes three components: a viscoelastic model for the postseismic deformation, an elastic block model for the overriding plates, and an elastic coupling model for the subduction interface. The need for an improved elastic block model for the overriding plates is clear in the residuals to the model of Suito and Freymueller [29]. In particular, sites on and near the Kenai Peninsula show a coherent and systematic trench-parallel residual after the subtraction of their best model. Because neither the elastic deformation associated with their block model nor their viscoelastic postseimic model predict any significant trenchparallel velocities, these residuals must reflect a failing of their block model. Thus their block model was replaced with a new three-block model for southern Alaska: the Southern Alaska (SOAK) block south of the Denali fault, 


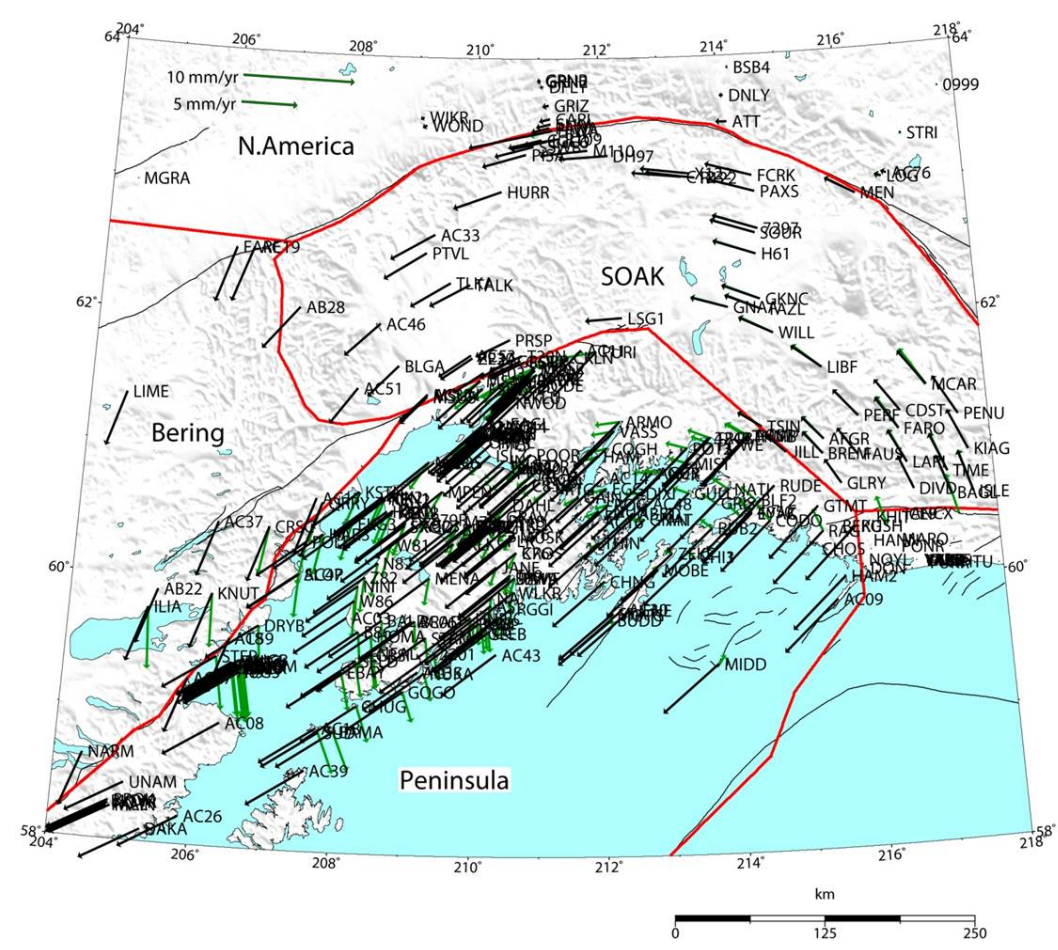

Figure 2. Predicted velocities for the new three-block model (black) and the old block model used in [29] (green). Where only the black vectors are visible, the two models are identical. Block boundaries are shown in red. The Yakutat block (bottom right) is not yet included in the model.

the Peninsula block for the Kenai and Alaskan Peninsulas, and the Bering plate [10] for the Bering Sea coastal region. Predicted velocities for the model are shown in Figure 2, compared with the predictions of the model presented in Suito and Freymueller [29]. Velocities for the elastic coupling and 1964 postseismic components for the subduction zone are not shown in this figure. This block model is used with a revised model for the elastic coupling, estimated by the same method as Suito and Freymueller [29] but using the new upper plate block model. The changes in the elastic coupling model are fairly small, although less smoothing of the plate interface slip deficit distribution had to be applied when the improved upper plate block model was used. Residuals for the new model are substantially lower than in Suito and Freymueller [29], and are well within uncertainty bounds for almost all sites on the Kenai Peninsula. There are still some significant residuals east of Prince William Sound and near the southern extent of Cook Inlet.

The HTDP velocity grid computed for this region equals the sum of three contributing velocity grids. The first of these three grids quantifies velocities for the upper plate model shown in Figure 2. The second quantifies velocities for a postseismic deformation model associated with the 1964 earthquake [29]. The third quantifies velocities for the elastic deformation computed from an interplate slip deficit model, following Suito and Freymueller [29]. Each of the three contributing grids were evaluated at a $15^{\prime}$ by $15^{\prime}$ spacing, and then the three grids were summed together to produce the velocity grid for this region.

\subsection{St. Elias velocity model}

The St. Elias region, located east of Prince William Sound, is notable for its complex deformation pattern and large velocities relative to the North America plate. Part of the region also includes a large postseismic signal from the 2002 Denali Fault earthquake. Fortunately, a dense set of GPS-derived velocity vectors across the region is available, and simple interpolation of these vectors produces an acceptable velocity field.

The interpolation was done with the GMT software [31]. The 3D velocity components were separated into three separate files for the east, north, and up components. Simulated velocity vectors based on the block model of Elliott et al. [13] were added for several offshore locations to ensure that the interpolation would be reasonable at all onshore locations. In each of the horizontal dimensions some data smoothing was done using GMT's blockmedian filter, and then a surface was fit using GMT's surface utility with its option for a spline under tension. Then a 15' by 15' grid in latitude and longitude was generated by sampling the surface at the nodes of this grid using GMT's grdtrack utility. Figure 3 shows the interpolated grid. The interpo- 


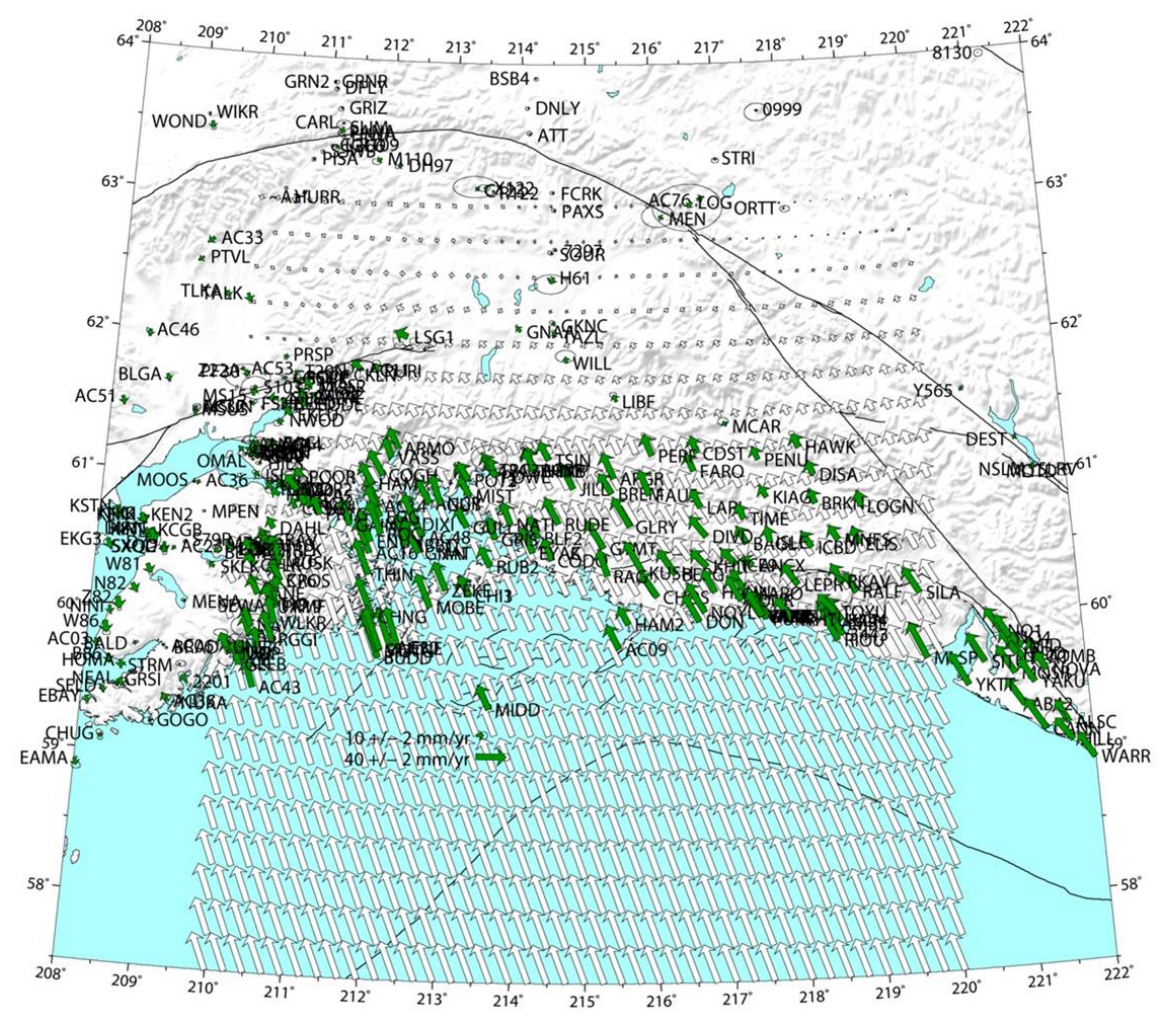

Figure 3. Observed (green) and interpolated (white) velocities for the St. Elias region. The computed interpolation grid extends beyond the limits of the grid used for HTDP to minimize edge effect.

lation covered a larger area than the grid used for HTDP to minimize edge effects.

\subsection{Mainland Alaska velocity model}

There are few data available for western and northern Alaska, and velocities relative to the North America plate are slow. A geophysical model provided no advantage over a simple interpolated model for this region. An interpolated model for most of Alaska (excluding the Aleutian Islands) was constructed using the same procedure as for the St. Elias region. The main difference is in the parameters for a blockmedian filter-because of the sparse data, a much coarser blocking of the data was done. This makes the model fit poorly in areas experiencing large spatial gradients in deformation, but HTDP does not use the Mainland velocity grid in these areas because these are regions where the other three Alaskan velocity grids are available. Figure 4 shows observed (i.e., GPS-derived) velocities for locations north of latitude $65^{\circ} \mathrm{N}$.

\section{Postseismic motion model for the Denali Fault earthquake}

The 2002 Denali Fault earthquake produced substantial postseismic displacements over a large swath of central
Alaska. These postseismic displacements require the addition of a new type of model component into the HTDP software. The postseismic deformation, in reality, is a combination of two main physical processes: (a) afterslip on the fault plane or deeper extension of the fault, and (b) viscoelastic relaxation in the upper mantle. Based on current theory, these two components are expected to have approximately logarithmic and exponential decays with time, respectively [6]. The full GPS-derived time series of positions cannot be fit to their measurement precision by a single relaxation process. However, except for a few months after the earthquake, the displacements can be fit acceptably well for the purposes of HTDP by using a single exponential relaxation model as expressed by equation (2). Use of a single process makes it simple to grid the associated coefficients $A_{i j}(\varphi, \lambda)$, making for a clean separation of spatial and temporal variations. Here $i$ represents the Denali Fault earthquake; and $j=$ north, east, or up.

The grid for the postseismic deformation was computed in two steps. In the first step, the long-term pre-earthquake $3 \mathrm{D}$ velocity was subtracted from the observed time series of positions for all sites in the region. The residual postearthquake time series for each station were then used to fit equation (2), plus seasonal variations for continuous GPS sites, where $\tau_{i}$ equals 2002.843 (= November 3,2002$)$ and $\nu_{i}$ equals 5.0 years. This time constant was chosen to mini- 


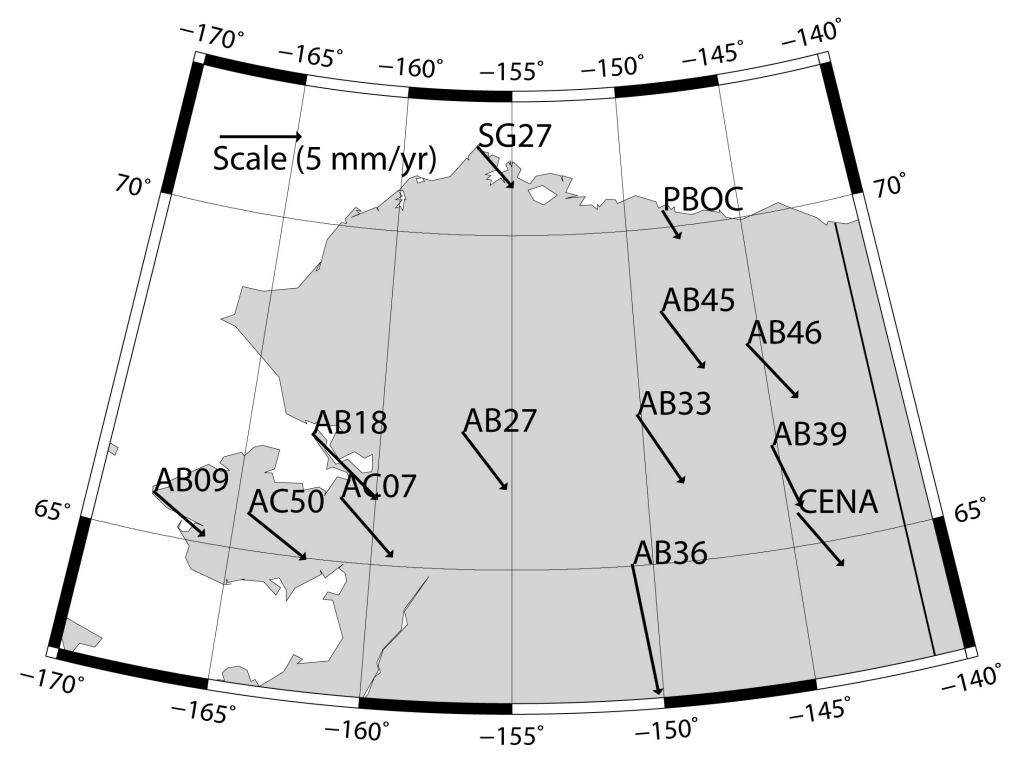

Figure 4. Observed velocities relative to stable North America for the region of Alaska located north of latitude $65^{\circ} \mathrm{N}$.

mize the misfit to the time series for times $>6$ months after the earthquake, using a few continuous GPS sites that had large signals to gauge the misfit. The estimated amplitudes $A_{i j}(\varphi, \lambda)$ were then saved for each station; each amplitude represents the total postseismic displacement at the station as time goes to infinity. All continuous and episodic sites that had sufficient data were used for our modeling process. Figure 5 shows the locations of the geodetic sites at which values for $A_{i j}(\varphi, \lambda)$ were estimated. Figure 6 shows the positional time series for a sample of five of these sites.

The second step was an interpolation of the total postseismic displacements $A_{i j}(\varphi, \lambda)$ for each value of $j$, in a similar manner to our interpolated velocity models. One key difference is that the spatial resolution of the initial interpolated grid had to be much finer than that used for other interpolations in order to capture the fine structure of the displacements near the fault. The resulting grid has a $7.5^{\prime}$ by $7.5^{\prime}$ spacing, and it spans the rectangular region residing between latitudes $60^{\circ} \mathrm{N}$ and $66^{\circ} \mathrm{N}$ and longitudes $135^{\circ} \mathrm{W}$ and $150^{\circ} \mathrm{W}$. Pseudo-observations of zero postseismic displacement at the fault were added in regions that had sparse near-fault GPS data. Postseismic deformation in general will be zero at or near the fault for all cases of strike-slip faulting, except where shallow afterslip occurs. This forces the zero crossing of the interpolated grid to be in approximately the right place, so that the asymmetry of the observed deformation will be correctly represented in the model. Figure 5 presents a contour map showing postseismic displacements estimated to have occurred during the 10-year period immediately following the Denali Fault earthquake.

\section{Discussion of the Alaskan models}

Figure 1 indicates that, north of latitude $64^{\circ} \mathrm{N}$, most of Alaska is moving southeastward at rates of less than $6 \mathrm{~mm} / \mathrm{yr}$ relative to stable North America. Figure 7 presents differences between ITRF2008 velocities from our composite velocity model and IGS08 velocities computed by Griffiths et al. [16] at several stations in the U.S. CORS network. (As demonstrated in Section 8, IGS08 velocities, in general, are well aligned to ITRF2008 velocities.) Although Griffiths et al. used essentially the same GPS data as that used for this study, their computations and this study's computations were performed independently of each other. The velocity vector differences shown in Figure 7 have a weighted RMS of $1.94 \mathrm{~mm} / \mathrm{yr}$ in the east-west dimension and $1.55 \mathrm{~mm} / \mathrm{yr}$ in the north-south dimension. These differences reflect errors in this study's velocity model as well as errors in the velocity vectors derived by Griffiths et al. However, some of these velocity vector differences are due to time-dependent deformation that has occurred over the past 15 years. In particular, neither this study's model nor the velocities of Griffiths et al. account for two timedependent events: a 1998-2001 slow slip event in the upper Cook Inlet area [21], and a change in velocities in the lower Cook Inlet area that took place in 2004 [14]. In both cases, limitations in the temporal sampling of the data make it difficult to develop a geophysical model that can be extrapolated with confidence. Data observed in 2011, not included in this work, suggests that further time-dependent events may be occurring again in both of these regions. Moreover, Figure 7 presents four velocity vector differences seemingly located at a single station near Cook Inlet. Actually, two of 


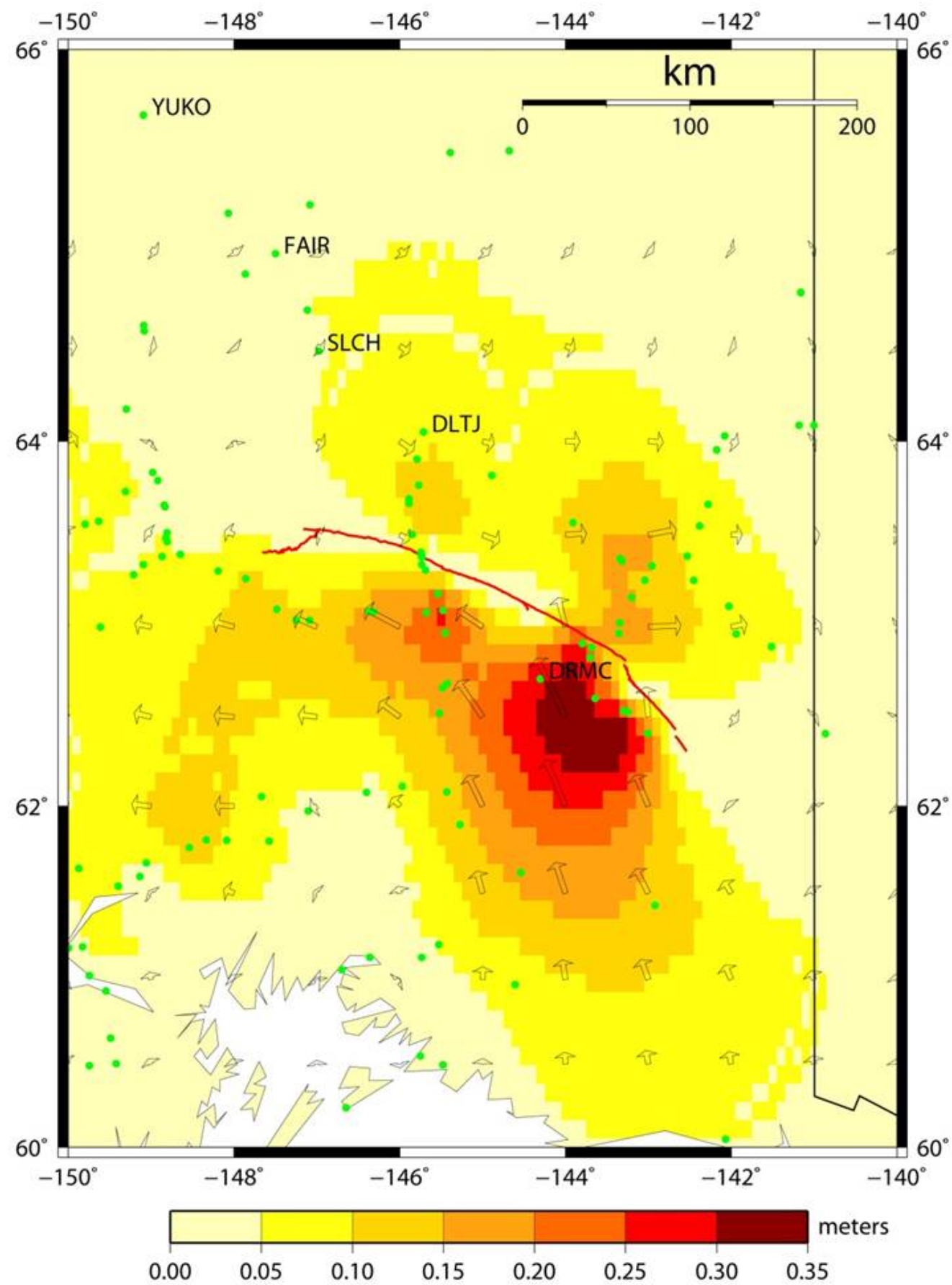

Figure 5. Green dots identify locations of GPS sites used to estimate postseismic motion associated with the Denali Fault earthquake. Labels identify the five sites whose positional time series are presented in Figure 6. Contours show the cumulative postseismic displacements estimated to have occurred during the 10-year period immediately following the earthquake. For clarity, interpolated displacements are shown at a 30' by 60' spacing. The red curve identifies the surface trace of that part of the Denali fault which ruptured during the 2002 earthquake. 

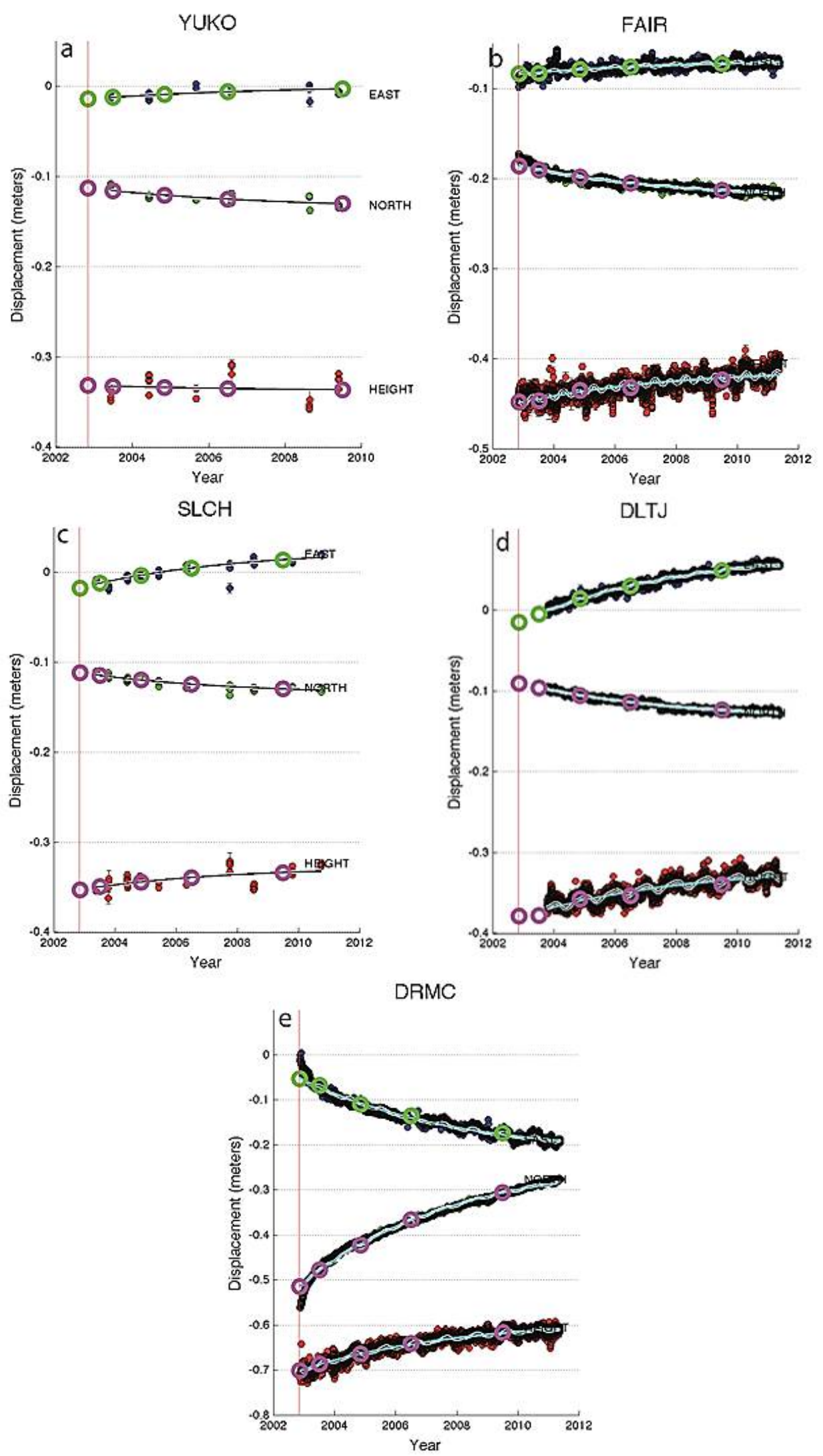

Figure 6. Sample of positional time series used to model the postseismic motion associated with the Denali Fault earthquake. 


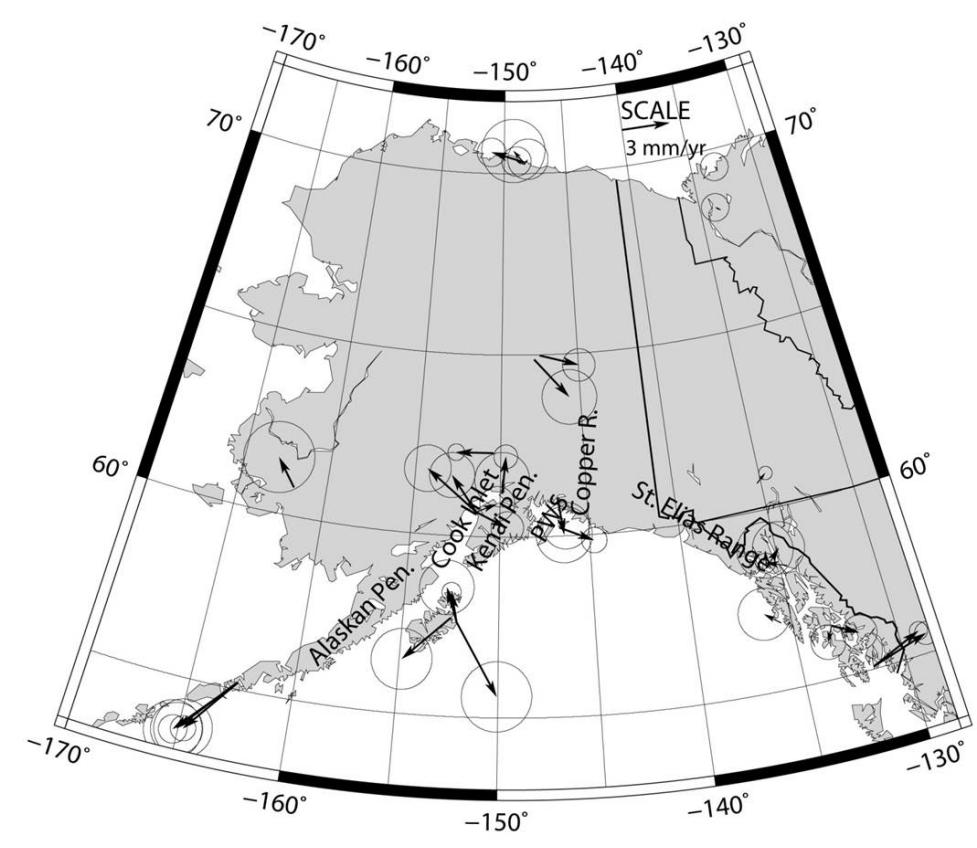

Figure 7. Differences between independently computed velocities and ITRF2008 velocities from HTDP's composite Alaskan velocity model. Circles represent $95 \%$ circular confidence regions for the independently computed velocities. The label "PWS" identifies the approximate location of Prince William Sound. The two continuous GPS stations, KEN1 and KEN2, are located at the base of the letter "I" in the label for Cook Inlet.

these vectors are located at one station (KEN1) and two are located at another station (KEN2) where the two stations are located within a few tens of meters of each other. For each of these two stations, Griffiths et al. computed velocities for all of the GPS data observed before the 2002 Denali earthquake and separate velocities for all of the GPS data observed after this earthquake. The two preseismic velocity differences are each oriented eastward; the two postseismic velocity differences are each oriented westward. Although the computations of Griffiths et al. attribute the velocity changes at KEN1 and KEN2 to preseismic versus postseismic motion, we attribute these velocity changes to slow motion events in the vicinity of Cook Inlet.

As illustrated by the velocity variations occurring at KEN1 and KEN2, it is simply not possible at present to fully model the time series of positions for sites near Cook Inlet (and perhaps other areas) at the centimeter level using a constant velocity. In the vicinity of Cook Inlet, the best possible constant velocity approximation was made, but not all sites have the same measurement history, so inconsistencies in the velocity field can be as large as several $\mathrm{mm} / \mathrm{yr}$ here, because some stations include data across these events and others do not. Model errors at the few to several $\mathrm{mm} / \mathrm{yr}$ level are likely near Cook Inlet. Model errors are much smaller than the geophysical signals. The model should be reasonable when applied to data collected within the last several years, but caution should be applied in using the model with data from the 1990s.
In addition, in the Copper River Basin area and the western St. Elias Range (see Figure 7 for locations), there was a further change in velocities following the 2002 Denali Fault earthquake [18]. In this area, almost all of the data post-dates this earthquake, so the post-earthquake velocities were used as they were. Caution should be applied in using the model in this area prior to 2002. This area is almost completely unpopulated, and model errors are much smaller than the deformation signal itself.

Deformation in the area of eastern Prince William Sound and the transition to the western St. Elias range is complex and inconsistencies in the models may occur where grids based on block models and interpolated models meet. The boundaries between the grids were chosen to minimize discontinuities across the boundaries, and to isolate any remaining inconsistencies to remote areas where the model is unlikely to be evaluated.

\section{CONUS data}

To model horizontal velocities in Eastern CONUS, 3D velocity vectors derived from data collected at continuous GPS stations were employed. Only stations with at least three years of data were considered. These velocity vectors were obtained from two separate solutions:

- The International Earth Rotation and Reference System Service (IERS) solution that yielded the official 


\begin{tabular}{lll}
\hline Parameter & Units & NGS Solution \\
\hline$\dot{T}_{x}$ & $\mathrm{~mm} / \mathrm{yr}$ & $-0.01 \pm 0.02$ \\
$\dot{T}_{y}$ & $\mathrm{~mm} / \mathrm{yr}$ & $-0.01 \pm 0.02$ \\
$\dot{T}_{z}$ & $\mathrm{~mm} / \mathrm{yr}$ & $0.020 \pm .02$ \\
$\dot{R}_{x}$ & $\mathrm{nrad} / \mathrm{yr}$ & $0.000 \pm .01$ \\
$\dot{R}_{y}$ & $\mathrm{nrad} / \mathrm{yr}$ & $0.00 \pm 0.01$ \\
$\dot{R}_{z}$ & $\mathrm{nrad} / \mathrm{yr}$ & $0.000 \pm .01$ \\
$\dot{s}$ & $\mathrm{ppb} / \mathrm{yr}$ & $0.00 \pm 0.01$ \\
\hline
\end{tabular}

Table 3. Estimated parameter values for transforming derived velocities to ITRF2008. Uncertainties correspond to formal standard deviations.

ITRF2008 coordinates and velocities for stations in the IGS network $[1,2,8]$. This solution included GPS data observed between 1997.0 and 2009.5

- The NGS solution released on September 6, 2011 which provides IGS08-compatible coordinates and velocities for stations in the US CORS network, as well as for most IGS stations [16]. This solution used GPS data observed between 1994.0 and 2011.3.

Velocity vectors from each of the two individual solutions were then transformed into the ITRF2008 reference frame via the equations:

$$
\begin{aligned}
V_{x}(\text { ITRF2008 }) & =\dot{T}_{x}(i)+V_{x}(i)+\dot{s}(i) \cdot x \\
& +\dot{R}_{z}(i) \cdot y-\dot{R}_{y}(i) \cdot z \\
V_{y}(\text { ITRF2008) }) & =\dot{T}_{y}(i)+V_{y}(i)-\dot{R}_{z}(i) \cdot x \\
& +\dot{s}(i) \cdot y+\dot{R}_{x}(i) \cdot z \\
V_{z}(\text { ITRF2008) } & =\dot{T}_{z}(i)+V_{z}(i)+\dot{R}_{y}(i) \cdot x \\
& -\dot{R}_{x}(i) \cdot y+\dot{s}(i) \cdot z
\end{aligned}
$$

where $\quad\left[V_{x}\left(\right.\right.$ ITRF2008), $V_{y}\left(\right.$ ITRF2008), $V_{z}($ ITRF2008) $]$ represents the ITRF2008 velocity at a station with the $x$-, $y$-, and $z$-axes referred to an Earth-centered, Earth-fixed Cartesian coordinate system; and $\left[V_{x}(i), V_{y}(i), V_{z}(i)\right]$ represents the $3 \mathrm{D}$ velocity at the same station in reference frame $i$ (for $i=1,2$ ). Here $\dot{T}_{x}(i), \dot{T}_{y}(i)$, and $\dot{T}_{z}(i)$ are the rates of translation of ITRF2008 relative to frame $i$ in the directions of the three principal axes; $\dot{R}_{x}(i), \dot{R}_{y}(i)$, and $\dot{R}_{z}(i)$ are the rates of (counterclockwise) rotation of ITRF2008 relative to frame $i$ about the three principal axes; and $\dot{s}(i)$ is the rate of scale change of ITRF2008 relative to frame $i$. The values for the translation rates, the rotation rates, and the scale change rates were estimated in a least squares manner by using GPS stations that were involved in both solutions and subject to the constraints that the seven rates for frame $i=1$ (i.e., the IERS solution) each equals a value of zero. Table 3 presents the estimated values for the parameters. These results indicate that the
NGS-derived velocity vectors are already well aligned to ITRF2008, which is as expected because the IGS considers the 14-parameter transformation between IGS08 and ITRF2008 to be the identity function [24].

\section{Estimating velocities in Eastern CONUS}

To estimate the velocity field in Eastern CONUS, we employed the DYNAP-G (DYNamic Adjustment Program for Grids) software which was introduced by Snay et al. [28]. DYNAP-G accepts various types of geodetic data to estimate a 3D velocity vector for each node of a userspecified 2D grid in latitude and longitude, which spans a specified rectangular region on the Earth's surface. The software employs bilinear interpolation in reverse to transfer crustal motion information from geodetic sites to the grid nodes. With bilinear interpolation the velocity at a point depends only on the velocities of the four corners of the grid cell containing this point and on the position of this point relative to these four corners. That is, if $u(\lambda, \varphi)$ denotes the eastward velocity component at the point with longitude $\lambda$ (positive east) and latitude $\varphi$ (positive north), and if this point is located in the grid cell whose lower lefthand corner has longitude $\lambda_{i}$ and latitude $\varphi_{j}$, then

$$
\begin{aligned}
u(\lambda, \varphi) & =\left[u\left(\lambda_{i}, \varphi_{j}\right) \cdot B \cdot D+u\left(\lambda_{i+1}, \varphi_{j}\right) \cdot A \cdot D\right. \\
& +u\left(\lambda_{i}, \varphi_{j+1}\right) \cdot B \cdot C \\
& \left.+u\left(\lambda_{i+1}, \varphi_{j+1}\right) \cdot A \cdot C\right] \\
& /\left[\left(\lambda_{i+1}-\lambda_{i}\right) \cdot\left(\varphi_{j+1}-\varphi_{j}\right)\right]
\end{aligned}
$$

where

$$
\begin{aligned}
& A=\lambda-\lambda_{i} \quad B=\lambda_{i+1}-\lambda \\
& C=\varphi-\varphi_{j} \quad D=\varphi_{j+1}-\varphi
\end{aligned}
$$

Similar equations hold for the northward and upward velocity components at this point. Even though the function $u(\lambda, \varphi)$ is defined in a piecewise fashion (cell-by-cell), the mathematical expressions for two adjacent cells agree 
along their common edge because equation (4) is linear in both $\lambda$ and $\varphi$. That is, $u(\lambda, \varphi)$ is a continuous function of $\lambda$ and $\varphi$. Thus, DYNAP-G is appropriate for modeling those velocity fields that vary continuously as a function of location. DYNAP-G, conversely, should not be applied to model a spatially discontinuous velocity field, as is the case when surface creep occurs along a geologic fault.

For this application of DYNAP-G, a 30' by 30' grid spanning the rectangular region whose longitudes range between $66^{\circ} \mathrm{W}$ and $110^{\circ} \mathrm{W}$ and whose latitudes range between $24^{\circ} \mathrm{N}$ and $50^{\circ} \mathrm{N}$ was employed. Equation (4) was then used to form three observation equations for each GPSderived velocity vector (one equation for each of the north, east, and up velocity components) with the goal of estimating the $3 \mathrm{D}$ velocity at each grid node. The modeled region contains 787 velocity vectors computed for 641 geodetic stations. The number of velocity vectors is greater than the number of stations, because some stations have velocity estimates from both the IERS solution and the NGS solution and because some stations have velocity estimates for two or more intervals of time.

It was assumed that the standard deviation for each of the three components of a velocity vector may be expressed by an equation of the form

$$
\sigma=\left(f^{2} / T^{3}+g^{2} / T^{2}\right)^{0.5}
$$

as proposed by Mao et al. [19]. Here, $f$ represents a function of the magnitude of the white noise in the GPS observations used to compute the velocity vectors, $g$ represents a function of the magnitude of their flicker noise, and $T$ equals the time span of these GPS observations. As $T$ increases in value, Equation (5) becomes better and better approximated by the equation

$$
\sigma \sim g / T
$$

Because only those velocity vectors for which $T$ exceeds 3 years were considered, the simpler equation, namely equation (6), was employed in assigning standard deviations. In particular, the northward component, as well as the eastward component, of an observed velocity was assigned a standard deviation of $2.7 / T \mathrm{~mm} / \mathrm{yr}$ with $T$ measured in years, and the upward component of an observed velocity was assigned a standard deviation of 5.3/T mm/yr. The values for these standard deviations were obtained via an iterative process discussed in a subsequent paragraph.

Because the solution involves estimating 3D velocities at 4,717 grid nodes, some grid cells contain few or none of the 787 observed velocity vectors (especially the grid cells located in oceanic areas). The observed velocity information was thus supplemented with quasi-observations which stipulate that the velocity vector at a given grid node should approximate the weighted mean of the velocity vectors at its neighboring nodes. In particular, the quasi-observations for the eastward velocity at the node with longitude $\lambda_{i}$ and latitude $\varphi_{j}$ is expressed by the equation

$$
\sum_{k} \sum_{m}\left[\left(u\left(\lambda_{i+k}, \varphi_{j+m}\right)-u\left(\lambda_{i}, \varphi_{j}\right)\right) /\left(d_{k, m}\right)^{2}\right]=0
$$

where $k$ and $m$ each range from -1 to +1 with not both $k$ and $\mathrm{m}$ equaling zero together. Here $d_{k, m}$ denotes the distance (in kilometers) between the node at $\left(\lambda_{i}, \varphi_{j}\right)$ and the node at $\left(\lambda_{i+k}, \varphi_{j+m}\right)$. Similar quasi-observations were introduced for the northward and upward components of the velocity field. Hence, for each grid node we introduced three quasi-observations, each with an appropriate standard deviation. The magnitudes of the standard deviations essentially control the degree of smoothing, i.e., the smaller the standard deviation, the smoother the velocity field will be. For each of the eastward and northward components, a standard deviation of $(2 \mathrm{~mm} / \mathrm{yr}) /(100 \mathrm{~km})^{2}$ was chosen; for the upward component, a standard deviation of $(6 \mathrm{~mm} / \mathrm{yr}) /(100 \mathrm{~km})^{2}$ was chosen. Again, these standard deviations were obtained via an iterative process discussed in the following paragraph.

In the solution for estimating velocities at the grid nodes, each observed velocity component and each quasiobservation was weighted equal to the reciprocal of the square of its standard deviation. As previously mentioned, the standard deviations for both the observed velocities and the quasi-observations were chosen in an iterative manner. After performing a preliminary solution with some trial standard deviations, refined standard deviations were computed so that the sum of the squares of the weighted residuals divided by the solution's degrees of freedom would equal one when using these refined standard deviations in the final solution.

Figure 8 shows HTDP's composite horizontal velocity field for Eastern CONUS relative to the NAD 83(2011) Epoch 2010.00 reference frame, which is the official reference frame for U.S. federal geospatial activities. In this figure, the three green lines outline the area where HTDP's velocity model for Western CONUS [23] was allowed to take precedence over the new velocity model for Eastern CONUS. The domain for the western model and the domain for the eastern model overlap throughout the rectangular area bounded by longitudes $100^{\circ} \mathrm{W}$ and $110^{\circ} \mathrm{W}$ and latitudes $31^{\circ} \mathrm{N}$ and $49^{\circ} \mathrm{N}$. Everywhere within this rectangular area, horizontal velocities provided by the Eastern CONUS model differ by less than $1.5 \mathrm{~mm} / \mathrm{yr}$ in magnitude from corresponding velocities provided by the Western CONUS model. Also, most of the velocity differences exceeding $1.0 \mathrm{~mm} / \mathrm{yr}$ in magnitude occur west of longitude $107^{\circ} \mathrm{W}$. Pearson and Snay [23] had employed an elastic block approach to develop the HTDP model for Western CONUS. In the rectangular overlap area, the western model contains only a few large blocks, and thus the Western CONUS model allows for less spatial variation 


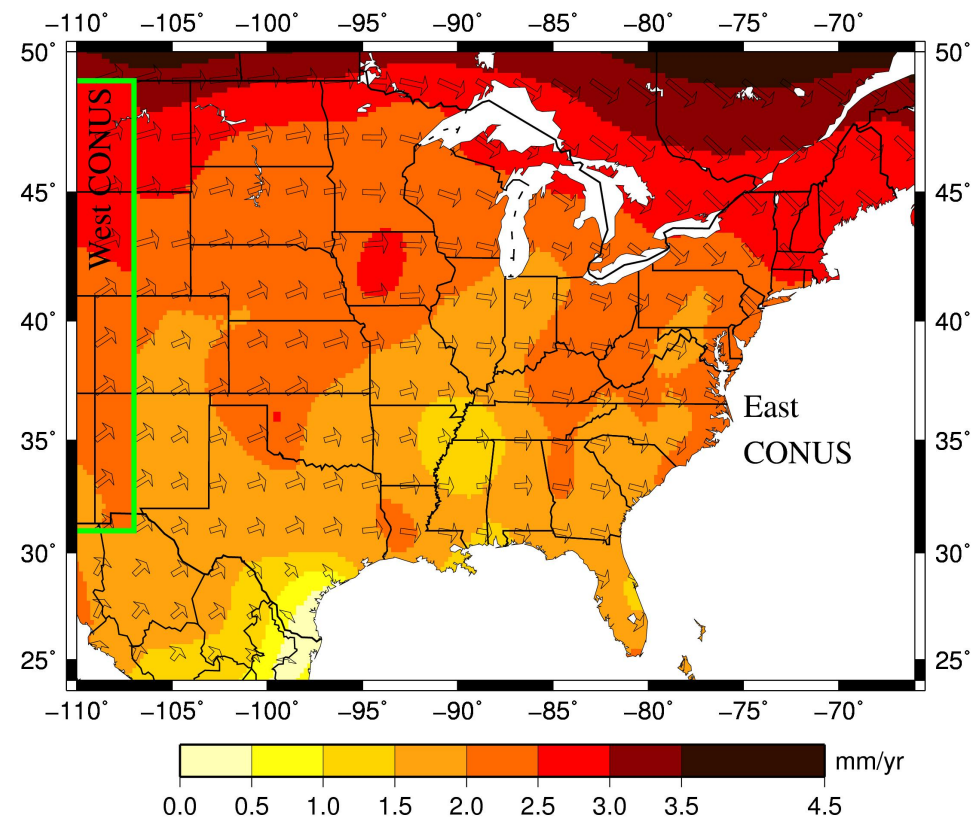

Figure 8. Estimates of NAD 83(2011) Epoch 2010.00 horizontal velocities obtained with HTDP_v3.2. Background colors represent velocity magnitudes, and arrows represent velocity magnitudes and directions. Green line segments designate the boundary between HTDP's model for Eastern CONUS and its model for Western CONUS.

among velocities than our eastern model in this overlap area. Velocity differences between the two models may also reflect edge effects for one model or the other. Because of concern for edge effects, longitude $107^{\circ} \mathrm{W}$ was chosen as the effective boundary between the two models within the HTDP software.

NAD 83 was designed so that locations within the stable part of the North America plate would experience little or no horizontal motion on average relative to this reference system [9]. Nevertheless, as seen in Figure 8, NAD 83(2011) Epoch 2010.00 velocity vectors exhibit significant systematic motion throughoutin Eastern CONUS. The source of this motion is discussed in Section 11 after considering estimates for actual motion relative to stable North America in Section 10.

DYNAP-G provides the standard deviation for each estimated velocity component at each grid node in the solution. The mean of the northward standard deviation and the eastward standard deviation was computed at each grid node and then this mean was multiplied by 2.5 to approximate the $95 \%$ circular confidence region associated with the estimated horizontal velocity at the node.

Figure 9 presents a contour map of the radii of these confidence regions. Figure 9 also shows residual velocity vectors (observed minus estimated) for the 787 estimated velocities located in Eastern CONUS.

Although a model for the vertical velocity field in Eastern CONUS was also developed, a discussion of vertical velocities will be postponed until a more comprehensive study of vertical motion in and around the United States can be performed.

\section{Velocities relative to stable North America}

Altamimi et al. [3] selected 44 continuous GPS stations which, in their estimation, reside within the stable part of the North America plate. These authors then employed the IERS-derived ITRF2008 horizontal velocities of these 44 stations to estimate the motion of stable North America relative to ITRF2008. They quantified this motion in terms of the rotation rates $\left(\dot{R}_{x}, \dot{R}_{y}, \dot{R}_{z}\right)$ about the $x$-axis, $y$-axis, and $z$-axis, respectively, plus translation rates $\left(\dot{T}_{x}, \dot{T}_{y}, \dot{T}_{z}\right)$ along these three axes. Here their estimated rotation rates $(0.035,-0.662,-0.100)$ milli-arc-seconds/yr and translation rates $(0.41,0.22,0.41) \mathrm{mm} / \mathrm{yr}$ are used to convert modeled ITRF2008 velocities for Alaska and Eastern CONUS into velocities relative to a fixed North-America-plate reference frame. Note that the model of Altamimi et al. [3] for the motion of stable North America differs from the one used in developing this study's Alaskan crustal motion models, because the model of Altamimi et al. was not available when the Alaskan GPS data were reprocessed for this study.

Figure 1 and Figure 10 present the resulting velocity fields for Alaska and Eastern CONUS, respectively, relative to stable North America. In creating Figure 10, only those velocities derived in this study were used. That is, none of the velocities that Pearson and Snay [23] derived for Western CONUS were used. Figure 10 indicates that most 


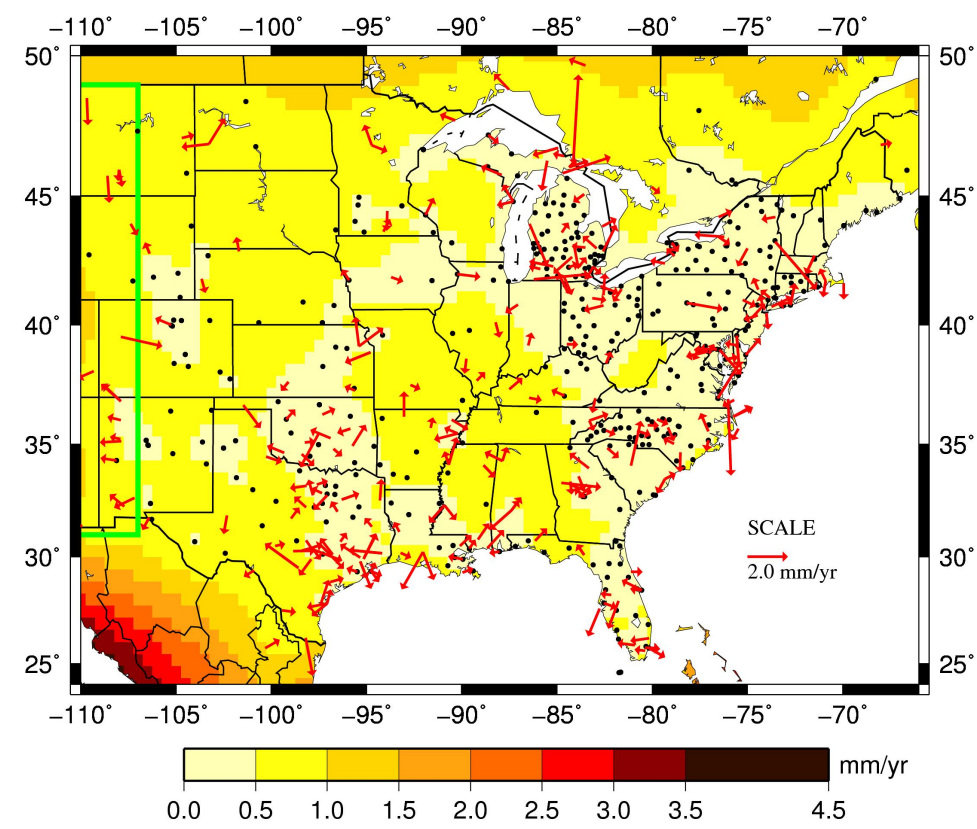

Figure 9. Background colors represent the radii of the $95 \%$ circular confidence regions for estimated horizontal velocities at the grid nodes. Red vectors correspond to the residual velocity vectors (observed minus estimated) each of whose magnitude exceeds $0.5 \mathrm{~mm} / \mathrm{yr}$. Black dots identify the locations of the GPS stations at which residual velocity vectors are less than $0.5 \mathrm{~mm} / \mathrm{yr}$ in magnitude. Green line segments designate the boundary between HTDP's model for Eastern CONUS and its model for Western CONUS.

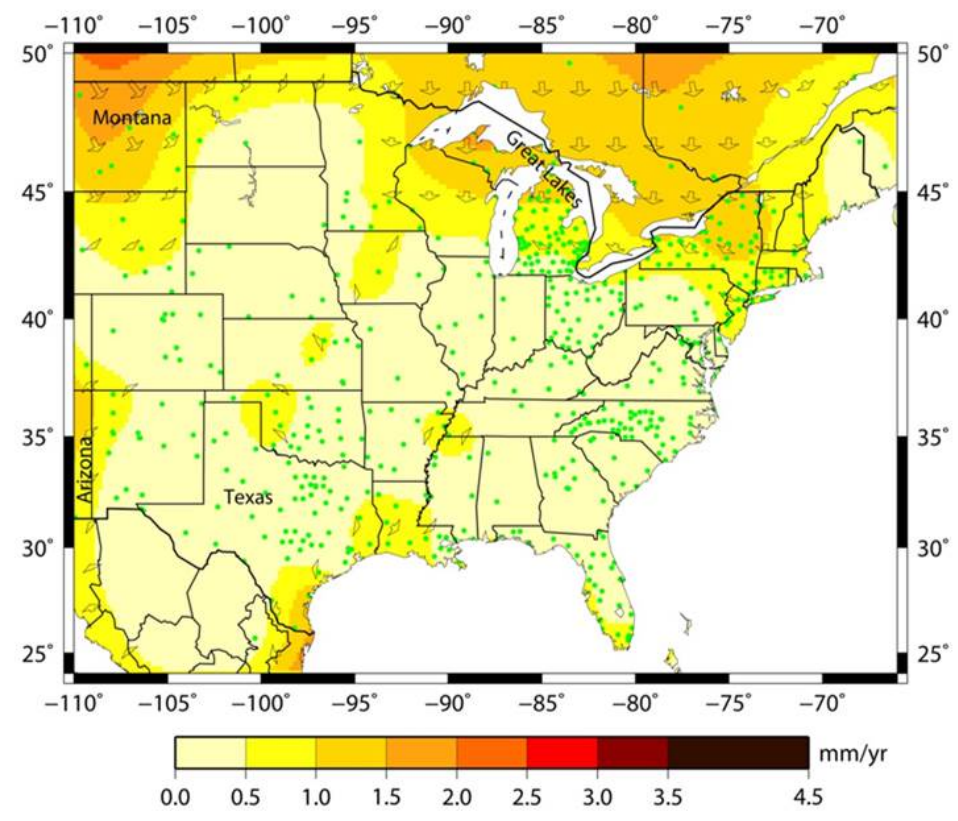

Figure 10. HTDP's estimated horizontal velocities relative to stable North America in and around eastern CONUS. Background colors represent velocity magnitudes. Interpolated velocity vectors are shown at a $2^{\circ}$ spacing when their magnitudes exceed $0.5 \mathrm{~mm} / \mathrm{yr}$. Green dots identify locations of GPS data points. 
of Eastern CONUS is moving less than $1 \mathrm{~mm} / \mathrm{yr}$, except in a few locations. Velocities with magnitudes exceeding $1 \mathrm{~mm} / \mathrm{yr}$ occur near the Great Lakes as well as to the north and east of the Great Lakes. Both Calais et al. [7] and Sella et al. [25] had previously identified such motion occurring near and adjacent to the Great Lakes, and they attributed this horizontal motion to glacial isostatic adjustment associated with the melting of Laurentide ice masses, which occurred more than 10,000 years ago. Horizontal velocities in this area are generally less than $2 \mathrm{~mm} / \mathrm{yr}$ in magnitude and exhibit flow directed outward from Hudson Bay where the Laurentide ice mass is thought to have been thickest during the Last Glacial Maximum. Figure 10 also indicates that horizontal velocities with magnitudes in excess of $1 \mathrm{~mm} / \mathrm{yr}$ occur in parts of Montana. Sella et al. [25] had previously identified similar motion in and around Montana, but the cause of this motion remains a mystery. Figure 10 also indicates that horizontal velocities, with magnitudes exceeding $1 \mathrm{~mm} / \mathrm{yr}$, occur in northwestern Arizona and in southern Texas. However, few or no GPS data points reside within the contours of the regions where such elevated velocities occur. Thus, the velocities exceeding $1 \mathrm{~mm} / \mathrm{yr}$, which occur in Arizona and Texas, may represent artifacts caused by the extrapolation of velocities from neighboring GPS data points.

\section{Velocities relative to NAD 83}

As documented in Table 7 of Pearson and Snay [23], the NAD 83(2011) Epoch 2010.00 velocity field relative to ITRF2008 is quantified by three rotation rates, $\left(\dot{R}_{x}, \dot{R}_{y}, \dot{R}_{z}\right)=(0.06667,-0.75744,-0.05133)$ milliarc-seconds/yr; plus three translation rates, $\left(\dot{T}_{x}, \dot{T}_{y}, \dot{T}_{z}\right)=$ $(0.79,-0.60,-1.34) \mathrm{mm} / \mathrm{yr}$; plus a scale change rate $=$ $-0.10202 \mathrm{ppb} / \mathrm{yr}$.

Now, the NAD 83 velocity field relative to stable North America may be approximated by subtracting from these seven rates the corresponding rates estimated by Altamimi et al. [3] which quantify the motion of stable North America relative to ITRF2008. (Note that the scale change rate of stable North America relative to ITRF2008 is assumed to equal zero.) The resulting rotation rates equal $(0.03167,-0.09544,0.04867)$ milli-arc-seconds/yr; the resulting translation rates equal $(0.38,-0.82,-1.75) \mathrm{mm} / \mathrm{yr}$; and the resulting scale change rate equals $-0.10202 \mathrm{ppb} / \mathrm{yr}$. The rotation rate corresponds to a clockwise rotation at a rate of 0.11172 milliarc-seconds/yr about a pole (through the geocenter) which pierces the Earth's surface near the point whose geographic latitude and longitude equal $25.8^{\circ} \mathrm{N}$ and $71.6^{\circ} \mathrm{W}$, respectively.

The motion of NAD 83 relative to stable North America occurs in part because NAD 83 is defined in terms of a 14-parameter transformation from ITRF96 which incorporates the NNR-NUVEL-1A plate motion model of DeMets et al. [12]. (See [9] for details.) Thus, the motion of NAD 83 is due in part to the motion of ITRF96 relative to ITRF2008 and in part to the inaccuracy of the NNRVUVEL-1A model. Also, part (though small compared to the other sources) of the motion of NAD 83 relative to stable North America is due to the glacial isostatic adjustment occurring near the Great Lakes, as well to the north and east of the Great Lakes, and due to the motion occurring in Montana.

\section{Summary}

NGS released HTDP_v3.2 in August 2012. This version of the software introduced: (a) an improved model for estimating interseismic horizontal velocities in Alaska, (b) a model for estimating the postseismic motion associated with the M7.9 Denali Fault earthquake, and (c) an improved model for estimating the interseismic horizontal velocity in Eastern CONUS. The Alaskan crustal motion models are based upon GPS data from both continuously and episodically occupied geodetic stations. The crustal motion model for Eastern CONUS is based upon GPS data from continuously occupied stations only.

The Alaskan interseismic velocity model is a composite of four regional models. For two of these regions (Southeast Alaska and South-central Alaska), elastic block models provide the basis for a geophysically reasonable representation of the velocity field. In the other two regions (St. Elias and Mainland Alaska) the GPS-derived velocity vectors were interpolated, because the associated geophysical models are complex and poorly constrained.

The postseismic motion associated with the Denali Fault earthquake was modeled as if the corresponding displacement rates decay exponentially over time with a relaxation constant of 5 years. The magnitude and direction of the cumulative postseismic displacements were estimated at each of several GPS stations, and then these displacements were interpolated throughout a rectangular region encompassing the area of significant motion.

The interpolation capability of the GMT software [31] was used to develop some of the Alaskan crustal motion models. However, the interpolation capability of the DYNAP-G software [28] was used to develop the model for Eastern CONUS. DYNAP-G enabled the uncertainty associated with the resulting velocity vectors to be estimated (Figure 9).

Finally, a recent estimate for the motion of stable North America relative to ITRF2008 [3] was used to convert estimated ITRF2008 interseismic velocities into velocities relative to stable North America. The results indicate that the Alaskan region located north of latitude $64^{\circ} \mathrm{N}$ is moving mostly southeastward at rates of less than $6 \mathrm{~mm} / \mathrm{yr}$. The 
results also indicate that interseismic velocities in Eastern CONUS have magnitudes less than $1 \mathrm{~mm} / \mathrm{yr}$, except near the Great Lakes and to the north and east of the Great Lakes and also in parts of Montana.

\section{Acknowledgments}

Development of the Alaskan models was performed primarily by personnel with the Geophysical Institute at the University of Alaska Fairbanks. Development of the Eastern CONUS model was performed primarily by NGS personnel. The authors thank the NGS team members, who processed the IGS and CORS data, for their diligence in performing this task. This team included Kevin Choi, Michael Cline, Robert Dulaney, Jake Griffiths, Stephen Hilla, William Kass, Gary Ray, Jim Ray, Jim Rhode, Mark Schenewerk, Giovanni Sella, Tomás Soler, Lijuan Sun, and Neil Weston. The authors also thank Michael Cline, Jake Griffiths, Dru Smith, Ronnie Taylor, and three anonymous reviewers for suggestions that improved the presentation this paper. This work was supported, in part, by the National Oceanic and Atmospheric Administration (NCNL1000-10-12607).

\section{References}

[1] Altamimi Z., Collilieux X., IGS contribution to ITRF, J.Geod. 83 (2009), 375-383, doi:10.1007/s00190-008-0294-x.

[2] Altamimi Z., Collilieux X., Métivier L., ITRF2008: an improved solution of the international terrestrial reference frame, J. Geod. 85 (2011), 457-473, doi:10.1007/s00190-0110444-4.

[3] Altamimi Z., Métivier L., Collilieux X., ITRF2008 plate motion model, J. Geophys. Res. 117 (2012), B07402, doi:10.1029/2011JB008930.

[4] Argus D. F., Gordon R. G., Heflin M. B., Ma C., Eanes R. J., Willis P., Peltier W. R., Owen S. E., The angular velocities of the plates and the velocity of Earth's center from space geodesy, Geophys. J. Int. 180 (2010), 913-960.

[5] Bird P., An updated digital model of plate boundaries, Geochem. Geophys. Geosyst. 4 (2003), 1027, doi:10.1029/2001GC000252 (see also http://peterbird. name/publications/2003_PB2002/2003_PB2002.htm).

[6] Bürgmann R. and Dresen G., Rheology of the lower crust and upper mantle: Evidence from rock mechanics, geodesy, and field observations, Annu. Rev. Earth Planet Sci. 36 (2008), 531-567, doi:10.1146/annurev.earth.36.031207.124326.

[7] Calais E., Han J. Y., DeMets C., Nocquet J. M., Deformation of the North American plate interior from a decade of continuous GPS measurements, J. Geophys. Res. 111 (2006), B06402, doi:10.1029/2005JB004253.

[8] Collilieux X., Métivier L., Altamimi Z., van Dam T., Ray J., Quality assessment of GPS reprocessed terrestrial reference frame, GPS Solut. 15 (2011), 219-231, doi:10.1007/s10291010-0184-6.
[9] Craymer M., Ferland R., Snay R., Realization and unification of NAD 83 in Canada and the U.S. via the ITRF, in Towards an Integrated Global Geodetic Observing System (IGGOS), Rummel R., Drewes H., Bosch W., Hornik H. (eds), IAG Section II Symp, International Association of Geodesy Symposia, Springer, Berlin 2000, 120, 118-121.

[10] Cross R. S., Freymueller J. T., Evidence for and implications of a Bering plate based on geodetic measurements from the Aleutians and western Alaska, J. Geophys. Res. 113 (2008), B07405, doi:10.1029/2007JB005136.

[11] DeMets C., Gordon R. G., Argus D. F., Geologically current plate motions, Geophys. J. Int. 180 (2010), 1-80, doi:10.1111/j.1365-246X.2009.04491.x.

[12] DeMets C., Gordon R. G., Argus D. F., Stein S., Effect of recent revisions to the geomagnetic reversal time frame on

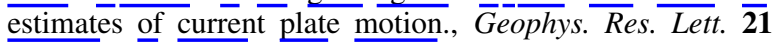
$\overline{(1994),} 21 \overline{9} 1-\overline{2194}$.

[13] Elliot J. L., Larsen C. F., Freymueller J. T., Motyka R. J., Tectonic block motion and glacial isostatic adjustment in southeast Alaska and adjacent Canada constrained by GPS measurements, J. Geophys. Res. 115 (2010), B09407, doi:10.1029/2009JB007139.

[14] Freymueller J. T., Along-strike and down-dip variations in subduction zone slip deficit: persistent or transient? Abstract T44B-03 presented at The Fall Meeting, Amer Geophys Union, San Francisco, Calif., 13-17 December 2010.

[15] Freymueller J. T., Woodward H., Cohen S., Cross R., Elliott J., Larsen C., Hreinsdóttir S., Zweck C., Active deformation processes in Alaska, based on 15 years of GPS measurements, in Active Tectonics and Seismic Potential of Alaska, AGU Geophysical Monograph, 179, Freymueller J. T., Haeussler P. J., Wesson R., Ekstrom G. (eds) American Geophysical Union, Washington, D.C., 2008, 1-42.

[16] Griffiths J., Rohde J. R., Cline M., Dulaney R. L., Hilla S., Kass W. G., Ray J., Sella G., Snay R., Soler T., Reanalysis of GPS data for a large and dense regional network tied to a global frame, IAG Commission 1 Symposium 2010, Reference Frames for Applications in Geosciences (REFAG2010), Marne-La-Vallee, France, 4-8 October 2010.

[17] Hreinsdóttir S., Freymueller J. T., Bürgmann R., Mitchell J., Coseismic deformation of the 2002 Denali Fault earthquake: Insights from GPS measurements, J. Geophys. Res. 111 (2006), B03308, doi:10.1029/2005JB003676.

[18] Johnson K., Bürgmann R., Freymueller J. T., Coupled afterslip and viscoelastic flow following the 2002 Denali Fault, Alaska earthquake, Geophys. J. Int., 176 (2009), 670-682, doi:10.1111/j.1365-246X.2008.04029.x.

[19] Mao A., Harrison C. G. A., Dixon T. H., Noise in GPS coordinate time series, J. Geophys. Res. 104 (1999), $\overline{27} \overline{97-28} \overline{16 .}$

[20] Okada Y., Surface deformation due to shear and tensile faults in a half-space, Bull. Seismol. Soc. Amer. 75 (1985), 11351154.

[21] Ohta Y., Freymueller J. T., Hreinsdóttir S., Suito H., A large slow slip event and the depth of the seismogenic zone in the south central Alaska subduction zone, Earth Planet Sci. Lett. 247 (2006), 108-116, doi:10.1016/j.epsl.2006.06.013.

[22] Pearson C., and Snay R., Updating HTDP for two recent earthquakes in California, Surveying and Land Information Science 67 (2007), 149-158.

[23] Pearson C., Snay R., Introducing HTDP 3.1 to transform coordinates across time and spatial reference frames, GPS Sol. 17 (2013), 1-15, doi:10.1007/s10291-012-0255-y. 
[24] Rebischung P., Griffiths J., Ray J., Schmid R., Collilieux X., Garayt B., IGS08: The IGS realization of ITRF2008, GPS Solut. 16 (2012), 483-494, doi:10.1007/s10291-011-0248-2.

[25] Sella G. F., Stein S., Dixon T. H., Craymer M., James T. S., Mazzotti S., Dokka R. K., Observation of glacial isostatic adjustment in "stable" North America with GPS, Geophys. Res. Lett. 34 (2007), L02306, doi:10.1029/2006GL027081.

[26] Schmid R., Steigenberger P., Gendt G., Ge M., Rothacher M., Generation of a consistent absolute phasecenter correction model for GPS receiver and satellite antennas, J. Geod. 81 (2012), 781-798, doi:10.1007/s00190007-0148-y.

[27] Snay R. A., Introducing two spatial reference frames for regions of the Pacific Ocean, Surveying and Land Information Science 63 (2003), 5-12.
[28] Snay R. A., Cline M. W., Philipp C. R., Jackson D. D., Feng Y., Shen Z. K., Lisowski M., Crustal velocity field near the big bend of California's San Andreas fault, J. Geophys. Res. 101 (1996), 3173-3185.

[29] Suito H., Freymueller J. T., A viscoeleastic and afterslip postseismic deformation model for the 1964 Alaska earthquake, J. Geophys. Res. (2009), doi: 10.1029/2008JB005954.

[30] True S. A., Planning the future of the World Geodetic System 1984, presented at The IEEE Position Location and Navigation Symposium, Monterey, California, 26-29 April 2004.

[31] Wessel P., Smith W. H. F., New, improved version of the Generic Mapping Tools Released, EOS Trans. 79 (1998), 579. 